\title{
Primary Adaptation Management of the Mining Faculties Graduates (by the Example of Coal Mining Enterprise)
}

\author{
Svetlana Smagina ${ }^{1, *}$, Oksana Kadnikova $^{2}$, Anastasia Rolgayzer $^{2}$, and Natalya Kanina ${ }^{1}$ \\ ${ }^{1}$ Kemerovo State University, Department of Psychology, 650000 Krasnaya St. 6, Kemerovo, Russia \\ 2 Plekhanov Russian University of Economics, Kemerovo Institute (branch), Department of \\ Humanities, 650992, Kuznetskiy Av. 39, Kemerovo, Russia
}

\begin{abstract}
The article highlights the problem of primary adaptation of graduates of higher and secondary vocational education institutions at Kuzbass coal enterprises. The main reasons for voluntary resignation of young specialists in the first year of their professional life are considered (by the example of JSC "UK Kuzbassrazrezugol" "Taldinsky ugolny razrez" and JSC "OUK Yuzhkuzbassugol"). The drawbacks of the existing adaptation programs are analyzed. The necessity of primary adaptation management is explained. The authors present a comprehensive program of adaptation activities as a necessary part of HR management which is aimed to retain a stable young staff at the enterprise. The program includes the development of a primary adaptation standard, description of organizing influence technologies at the initial stage of employment, methods of non-monetary incentives and final diagnostics of the adaptation indicators of newcomers. Risk factors inhibiting the adaptation process of graduates are also specified in the article. Testing of the primary adaptation program was carried out on the basis of "Taldinsky ugolny razrez", the largest coal mining enterprise of Kuzbass.
\end{abstract}

\section{Introduction}

The coal mining industry is one of the priority sectors in Kuzbass. Prospects for the development of coal enterprises ensure the formation of a young staff. Young staff members are the future effective replacement and the main resource of any organization. Mining graduates hold a specific place among young people working in mining enterprises and are in high demand among employers.

A significant number of graduates of secondary and higher vocational mining education have serious difficulties in moving from studies to the real conditions of modern mining production. The period of natural transition from educational to professional activity is a complex process of adapting a young inexperienced specialist to a new way of life, a new social role and responsibility, a new type of social relations and a qualitative complication of

${ }^{1}$ Corresponding author: kennedy22.1963@yandex.ru 
interaction with others. In addition, many graduates start their working life with unskilled underground work or low-level occupations.

\section{Materials and Methods}

The analysis of young employees' turnover (based on the example of a large coal mining enterprise JSC "OUK Yuzhkuzbassugol") shows that only net economic losses caused by dismissal or hiring are up to 2.5 thousand tons of coal per day with an average downtime about 19-20 days. Losses related to low productivity of newcomers and their mistakes in work, costs for training, registration of labor relations, compulsory medical check-ups paid by the employer and other necessary stranded costs in the situation of the employee's dismissal are also unavoidable. At the same time about $40 \%$ of the redundant workers are graduates with higher and secondary mining education. Personnel movement indicators at JSC "UK Kuzbassrazrezugol" "Taldinsky ugolny razrez" also demonstrate a positive dynamics of negotiated resignations of young employees. The high level of turnover coincides with the initial period of career development, namely with the first year of professional life.

The results of socio-psychological research, which are statistically proven, highlighted that the main reasons for voluntary resignation of young employees are subjective: dissatisfaction with pay levels, distanced indifference from other employees, discontent with schedule of work and, in some cases, with extreme mining and geological labor conditions, high standards in relation to occupational health and safety compliance, lack of prospects, disrespect from executives, an unfavorable climate in the work collective etc. [1]

The findings of diagnostics of reasons for voluntary resignation of the young employees of JSC "UK Kuzbassrazrezugol" "Taldinsky ugolny razrez" are agreed with the data obtained on the example of a large coal mining enterprise JSC "OUK Yuzhkuzbassugol". Thus, the improvement of the personnel management system towards the development and organizing of local events aimed at changing attitudes, stimulating and reducing anxiety, can increase loyalty and facilitate the process of entering yesterday's student into new professional and socio-economic working conditions [2].

Staff adaptation in the organization is a necessary part of personnel management. In the light of current concepts of HR management, adaptation is characterized as a two-way process of mutual adaptation of an employee to an organization, which is based on the gradual employee adaptability to new professional, psychophysiological, socio-psychological, organizational, administrative, economic, sanitary and living conditions [3, 4].

\section{Results and Discussion}

The results of the SWOT analysis carried out on the basis of JSC "UK Kuzbassrazrezugol" "Taldinsky ugolny razrez" revealed that one of the directions of the personnel management system - the primary adaptation strategy of young employees - must be optimized. Adaptation activities are fragmentary at the enterprise:

- output norms for the drivers of BelAZ trucks are selectively reduced during the period of mentoring and there is a single additional payment;

- a committee of young professionals works with an elected leader;

- the information support of young employees regarding the strategy, plans and prospects is stabilized;

- hot meals are organized in the workplace.

The goal of this primary adaptation management program is a mobile and effective mutual adaptation of a young employee to an organization taking into account the expectations of 
the organization and the capabilities of the employee. The program is aimed not only at retaining, but also securing a stable young staff.

The basis for the development of the project was the practice of the HR department and experience of the specialists in HR management of "Taldinsky ugolny razrez" and its partners as well as the fundamental principles of Management Psychology and Human Resource management theory.

The program of primary adaptation of young employees includes the following stages:

1) developing a standard of adaptation activities for young employees;

2) using technologies of organizing influence on young employees;

3) adjusting non-monetary incentives;

4) the evaluation of basic adaptation indicators of young employees.

The elaboration of the standard of adaptation activities includes: appointment of mentors and employees responsible for adaptation management in the units; selection of necessary adaptation activities and technologies; determination of the duration of each stage and forms of final control.

Mentoring plays a crucial role in primary adaptation of a graduate: the mentor makes possible not only to transfer professional and personal knowledge and skills that are specific to that particular organization, helps to fit in and master functional duties, but also is capable to motivate a young employee for further training, professional growth and provide him with psychological support [5]. Moreover, the development of mentoring in the modern coal mining enterprise is determined by the social and organizational expediency. A reputable, professional and mature employee contributes to developing of professional and personal communications of a young specialist in the social environment of the organization, thus stabilizing human resource processes in the team.

The effective stage of primary adaptation begins with bilateral awareness-raising activities (informing young specialists about goals, priorities, problems, norms and standards of output, products and its consumers, organizational structure, existing programs for employees, benefits package, etc.). Due to increased industrial safety requirements at coal mining enterprises, psychotechnology of self-motivation of young employees plays an important role in the informative aspects of work. Occupational safety and health training for newcomers includes not only the familiarization with professional instructions, precautions and warnings about potential hazards in the workplace. In addition, young employees are trained in first aid and self-help in case of emergency in panic, fear, anxiety, motor excitement, hysteria, apathy, aggression, nervous fever and other acute stress disorders.

Informing inexperienced employees about safety issues does not take the form of a "passive" instruction. By means of special manipulative methods of persuasive psychological influence, new employees form an active attitude toward the readiness of unconditional observance of labor protection requirements and stereotypes of safe professional behavior in a specific work collective as well as an intolerant attitude towards violators of security requirements $[6,7]$.

During this stage it is advisable to use less formalized technologies that are applied to specific adaptable young employees. In particular, the following adaptation activities have successfully proved themselves at "Taldinsky ugolny razrez": execution of a one-time community service to establish rapport between the new employee and the team; use of the method of gradual complication of tasks performed by the employee followed by constructive analysis of mistakes; special intensive short-term courses for the preparation of future mentors.

Taking into consideration the limitation of the financial resources for stimulating the young employees in the context of adaptation activities, particular attention is paid to issues of non-material incentives which are based on the business concepts of the owners of coal mining enterprises. Using the successful experience of non-material incentives of young 
miners of JSC "UK Kuzbassrazrezugol" "Taldinsky ugolny razrez", we will present the following forms of corporate adaptation activities that not only facilitate the adaptation of former students, but also have a motivational effect:

1) Carrying out a complex of corporate psychological trainings by HR managers oriented toward the development of group cohesion and the formation of a sense of team spirit among young employees; prevention of professional stress at the initial stages of mastering the profession in a situation of overwork, chronic-fatigue build, increased responsibility etc.; development of communicative competence which is especially important for a young specialist with higher technical education.

2) Carrying out some activities aimed at incorporating the former graduate into a new system of in-house communications, developing an organizational culture and increasing selfgratification (gifting items with company logo, declaring achievements of new employees, introducing competition elements between or within the unit where young employees work).

3) Encouraging education (corporate training or reskilling on the basis of its own Personnel Training Center in accordance with the training needs of the organization itself and the professional goals and interests of the employee taking into account the periodicity of vocational training).

4) Encouraging through social services (conclusion or prolongation of contracts with preschool educational institutions, providing them with sponsorship for the purpose of admitting the children of the staff at pre-school, the introduction of "children's days" (if a young employee has a child, he is entitled to take five paid free days during the year).

5) Career management of a young employee is determined on the basis of the quantitative and qualitative needs of the organization for managerial staff, taking into consideration the time factor. The preconditions for career planning are formed at different stages of the adaptation period and outside it: an interview during the selection process - hiring - the end of the probation period - the development of a succession pool [8,9]. Self-acceptance and the coordination of the company's expectations with the professional and personal characteristics and professional goals of the graduate, related to career building, opportunities and fears of the employee are the main criteria of success [10]. An effective tool for career management is also an individual career map for monitoring and recording activities to work with succession pools that describes the professional and personal characteristics of the young employee, the goals and dynamics of his professional advancement during 5-7 years, the development level of his professional competencies, the dynamics of his achievements and specific results over the reporting period.

The experience in using this technology shows that the introduction of the individual career map not only gives a clearer vision of the personal and professional perspectives of a particular employee, but it is also an important indicator of monitoring and recording activities to work with succession pools throughout the organization [11]. A purposeful, ambitious, oriented to building a professional career graduate is a potential candidate for any key position. "Vertical" growth of such specialists automatically solves the problems of reducing staff turnover and increasing labor productivity [12].

6) The active involvement of young employees in participating in corporate events which keep up established traditions (annual sports competitions, professional skills competitions, master classes, etc.).

The final stage is the diagnostics of the adaptation indicators of young employees. The effectiveness of the developed program of supporting graduates will be determined by the availability of optimal adaptation indicators [13]. Carrying out a series of diagnostic procedures allows realizing the control of this process.

Diagnostics of adaptation indicators is carried out in five directions:

- The expert assessment of professional and personal adequacy of a young employee.

- The evaluation of employee satisfaction with various aspects of work in the organization. 
- The evaluation of employer satisfaction (direct supervisor, mentor and other experts) with various aspects of the work of a newcomer.

- Diagnostics of the motivational profile of young employees and monitoring the dynamics of their development (if the structure of labor motivation is optimal).

- Emotional and evaluative attitude toward the staff of the organization.

Testing of the primary adaptation program of graduates was carried out on the basis of JSC "UK Kuzbassrazrezugol" "Taldinsky ugolny razrez", the largest enterprise of Kuzbass specializing in open-pit coal mining. The graduates of Kuzbass State Technical University and mining schools of Leninsk-Kuznetsk and Prokopyevsk were involved in testing. The results, obtained during the implementation of the primary adaptation program, confirm its effectiveness. Young employees demonstrated the following adaptation indicators:

- the optimum level of professional and qualification characteristics and professionally important qualities (moderate level of satisfaction with work activity (overall average level of expert assessments), development of necessary professional skills, motivation for professional and personal growth, ability to maintain the required level of discipline, relative independence in the performance of job functions, desire to be responsible for the results);

- personal satisfaction with the organization (content of job, working conditions, hours of operation, career opportunities);

- the predominance of external positive motivation in the form of a combination of the profit motive and career growth as well as internal positive motivation - the pleasure from a good job. The motivation to avoid punishment and criticism from the leadership is poorly expressed;

- satisfaction with the psychological climate and managerial style in the organization.

The main problems and difficulties in the implementation of the primary adaptation management project were related to the lack of feedback from both the newcomers and the staff of the organization who is involved in this process as well as the difficulties in monitoring internal interpersonal processes and overcoming critical attitude of some managers of department. The economic efficiency of the program (because of the lack of investment) is proved. The results of the study show that discontent with salary level is the main threat blocking the adaptation process of graduates and young employees in whole.

\section{Conclusion}

The current conditions for the operation of coal enterprises determine the need to prioritize personnel policy and apply effective methods of working with staff. Technologies of the primary adaptation of graduates are crucial for the prospects of harmony and stability of HR processes in the organization.

The program of adaption activities presented in this article includes the following stages and aspects of work: specification of the standard of primary adaptation, description of the technology of an organizing impact on newcomers (informational and educational activities, methods of gradual complication of tasks etc.); corporate methods of non-monetary incentives of young employees (career management methods, declaring achievements, introducing "Children's days", corporate training etc.); diagnostics of adaptation indicators. The proposed program of primary adaptation management was tasted at JSC "UK Kuzbassrazrezugol" "Taldinsky ugolny razrez".

\section{References}

1. G. Chistyakova, E. Bondareva, K. Demidenko, E. Podgornaya, O. Kadnikova, E3S Web of Conferences, 15, 04010 (2017) 
2. G. Pinigina, I. Kondrina, S. Smagina, E3S Web of Conferences, 15, 04017 (2017)

3. J. Song, Y. Zhu, F. Dong, Cross Strait Quad-Regional Radio Science and Wireless Technology Conference, 24, 01124 (2011)

4. F. Mingchao, S. Bin, Digital Manufacturing \& Automation, 25, 03124 (2011)

5. M. Zwetsloot, J. Aaltonen, J. Wybo, P. Saari, R. Kines, Op De Beeck, Safety Science, 58:3, 89-98 (2013)

6. S. Smagina, O. Kadnikova, K. Demidenko, G. Chistyakova, A. Rolgayzer, E3S Web of Conferences, 21, 04020 (2017)

7. M. Evans, Journal of Management, 12:2, 203 (2006)

8. H. Lloyd, E. Ogbonna, Journal of Business Reseach, 51:2, 98 (2001)

9. J. Gebhart, Sloan Management Review, 38:4, 45509 (1997)

10. L. Herscovitch, J. Meyer, Journal of Applied Psychology, 87:4, 987-995 (2002)

11. S. Madsen, D. Miller, C. John, Human Resource Development Quarterly, 16:4, 100-109 (2005)

12. L. Drupsteen, G. Groeneweg, G. Zwetsloot, Journal of Occupational Safety and Ergonomics, 19:1, 80-89 (2013)

13. A. Bandura, Current Directions in Psychological Science, 9 :3, 521-528 (2000) 